\title{
ANALISIS WACANA HATE SPEECH DALAM LIVE STREAMING YOUTUBE LIGAGAME E-SPORTS TV
}

\author{
Thomas Dewo Ayudya ${ }^{1}$ \\ Bonardo Marulitua Aritonang ${ }^{2}$ \\ Ester Krisnawati ${ }^{3}$
}

\begin{abstract}
Technological development on online communication was creating various communication on internet, one of them is live streaming features in Youtube. Communication variation in internet evidently still has a problem, one of them is the existence of hate speech on comment section in live streaming Youtube of Ligagame eSports TV Youtube Channel. Theory of Discourse from Ernesto Laclau and Chantal Mouffe become guidelines to analyze the discourse formed from caster so that appeared hate speech from audience comment, which that hate speech divided to some type of cyberbullying. To analyze that, the researcher do observation or direct observe when live streaming been held and interview part of Kominfo Salatiga as a data triangulation. The result of research show that delivery like anything brought by the caster in streaming would still bring up hate speech comment from audience, and a caster can react with reply the hate speech argument from the audience, offer solution to stop hate speech from appearing, or just ignore that comment.
\end{abstract}

Keyword: Hate Speech, Caster, Discourse, Youtube, Cyberbullying.

\begin{abstract}
Abstrak
Perkembangan teknologi dalam komunikasi secara online telah menciptakan beragam. komunikasi dalam internet, salah satunya adalah fitur live streaming di Youtube. Berkembangnya variasi komunikasi di internet ini ternyata tetap memiliki permasalahan, salah satunya adalah adanya komentar-komentar bernada hate speech dalam live streaming Youtube di salah satu kanal Youtube Ligagame eSports TV. Teori wacana Ernesto Laclau dan Chantal Mouffe menjadi pedoman dalam menganalisis wacana yang terbentuk dari seorang caster sehingga muncul hate speech dari komentar penonton, dimana hate speech tersebut terbagi ke dalam jenis-jenis cyberbullying. Untuk menganalisisnya, peneliti melakukan observasi atau mengamati langsung ketika live streaming berlangsung dan mewawancarai pihak dari Kominfo Salatiga sebagai triangulasi data. Hasil penelitian menunjukkan bahwa pembawaan seperti apapun yang dibawakan seorang caster dalam streaming akan tetap memunculkan komentar hate speech dari penonton, dan seorang caster dapat bereaksi dengan cara membalas argumen dari hate speech penonton, menawarkan solusi untuk menghentikan munculnya hate speech, atau mengabaikan komentar tersebut.
\end{abstract}

Kata Kunci: Ujaran Kebencian, Caster, Wacana, Youtube, Intimidasi Dunia Maya

\footnotetext{
${ }^{1}$ Mahasiswa Prodi Ilmu Komunikasi, Fakultas Ilmu Sosial dan Ilmu Komunikasi, UKSW Salatiga

${ }^{2}$ Dosen Prodi Ilmu Komunikasi, Fakultas Ilmu Sosial dan Ilmu Komunikasi, UKSW Salatiga

${ }^{3}$ Dosen Prodi Ilmu Komunikasi, Fakultas Ilmu Sosial dan Ilmu Komunikasi, UKSW Salatiga
} 


\section{PENDAHULUAN}

Media sosial kini menjadi bagian tak terpisahkan dari kehidupan manusia dan telah dikonsumsi secara masif. Tak mengherankan, kehadiran media sosial menjadi fenomenal. Media sosial Facebook, Twitter, Instagram hingga YouTube menjadi platform yang paling diminati oleh khalayak. Media sosial tidak hanya digunakan untuk mendistribusikan informasi yang bisa dikreasikan oleh pemilik akun (user) itu sendiri, tetapi juga memiliki dasar sebagai portal untuk membuat jaringan pertemanan secara virtual dan medium untuk berbagi data, seperti audio atau video (Nasrullah, 2015: 3). Namun tak dipungkiri bahwa peran media sosial dapat diibaratkan seperti pedang bermata dua, satu sisi dia bisa digunakan untuk kegiatan positif, disisi lain media sosial bisa digunakan untuk hal-hal yang negatif dan merugikan masyarakat. Berita-berita Hoax (berita palsu) dan Hate Speech (ujaran kebencian) atau Cyber-Bullying (perundungan siber) kini banyak kita jumpai di media sosial dengan berbagai bentuk dan tampilan gaya bahasa yang provokatif.

Hate Speech menurut David O. Brink dalam Anam dan Hafiz (2015) dipandang lebih buruk dari sekedar pernyataan yang diskriminatif, dimana hate speech menggunakan simbol tradisional untuk melecehkan seseorang karena keterikatannya pada kelompok tertentu dan sebagai ekspresi dari penghinaan kepada targetnya agar menimbulkan efek kesengsaraan secara psikologis. Berdasarkan hal ini, hasil konstruksi sosial ini menentukan bagaimana seseorang memberikan reaksi terhadap suatu konten pesan yang dibagikan di internet. Hate speech sendiri biasanya lebih mengarah ke unsur SARA (Suku, Agama, Ras, Antar golongan).

Platform media sosial YouTube yang digunakan untuk berbagi video melengkapi fiturnya dengan kolom komentar bagi para netizen atau warga net yang ingin menyampaikan sesuatu terhadap konten video yang diunggah. Namun pesan dalam kolom komentar itu cenderung mengandung pernyataan yang mengarah kepada ujaran kebencian atau Hate speech. Hate speech di YouTube dapat dilihat dari komentar sebuah postingan video maupun video livestream. Pesan berupa hate speech ini biasanya lebih mengarah ke komunikator atau pembuat video atau livestream YouTube, baik dari cara penyampaian pesan melalui konten videonya, gestur saat menyampaikan pesan, gaya bicara yang digunakan, hingga ke penampilan fisik si komunikator tersebut.

Melihat banyaknya YouTuber yang melakukan live streaming di platform YouTube mengundang daya tarik penonton untuk melihat, hingga ikut menanggapi konten-kontennya.

Kebebasan berpendapat di era reformasi ini telah mengubah wajah masyarakat Indonesia sebagai pengguna media sosial. Hal itu tentu berkontribusi dengan cara netizen mengomentari konten-konten di media sosial. Menurut pengamatan peneliti, motivasi penonton live streaming YouTube diantaranya ingin memenuhi kebutuhan informasi, sarana hiburan hingga keinginan berkomunikasi lewat mengomentari konten-kontennya, baik dengan maksud menghina maupun merendahkan streamer (komunikator). Platform YouTube yang kini mudah diakses masyarakat berkontribusi munculnya tindakan-tindakan menyimpang dalam penggunaannya, bahkan sulit dikontrol. Tak sedikit para pengguna media sosial YouTube membuat akun palsu untuk menyembunyikan identitas aslinya. Alhasil, para pemilik akun-akun palsu itu bisa dengan bebas memberikan kritikan yang mengandung hujatan atau hinaan yang menjatuhkan orang-orang yang melakukan live streaming. Reaksi beragam pun bermunculan, baik dari caster (komunikator) yang akan merespon komentar itu, maupun viewers (komunikan) yang ikut menanggapi topik pembicaraan tersebut. Hal tersebut peneliti amati saat menyaksikan live streaming YouTube, terutama siaran dengan konten permainan atau gaming, baik perorangan maupun kelompok atau komunitas tertentu yang melakukan live streaming.

Perkembangan media sosial yang berdampak pada cara berinteraksi masyarakat tak lepas dari perhatian pemerintah. Regulasi mengenai interaksi dunia maya termasuk yang terkait dengan hate speech diatur dalam Undang-Undang No. 11 Tahun 2008 Tentang Informasi dan Transaksi Elektronik Pasal 28 ayat (2) sehingga menjadi pedoman untuk mengantisipasi adanya hate speech di dunia maya. Dimana pasal 28 ayat (2) tersebut berbunyi "Setiap orang dengan sengaja dan tanpa hak menyebarkan informasi yang ditujukan untuk menimbulkan rasa kebencian atau permusuhan individu dan/ atau kelompok 
masyarakat tertentu berdasarkan atas Suku, Agama, Ras, dan Antargolongan (SARA)".

Kondisi tersebut membuat peneliti tertarik untuk mengetahui bagaimana wacana hate speech yang tercipta dari penonton (viewers) Youtube sebagai hasil dari interaksi antara seorang caster sebagai komunikator dengan penonton sebagai komunikan terhadap konten live streaming tersebut. Peneliti menggunakan sampel dari salah satu channel YouTube dengan konten gaming yaitu channel "Ligagame eSports TV"1. Kantor Channel YouTube yang berlokasi di Jl. Daan Mogot No.51, RT 9/RW 1, Kedoya Utara, Kebon Jeruk, Jakarta Barat ini sering menayangkan pertandingan antar tim eSports (Electronic Sports) yang biasanya tim dalam suatu permainan atau game secara live atau langsung. Dalam setiap penayangannya, Channel ini kerap membuka ruang diskusi antara caster dengan viwers atau kolom komentar yang memungkinkan munculnya beragam pendapat yang rentan dengan ujaran kebencian (hate speech).

\section{KAJIAN TEORITIS}

\section{Teori Analisis Wacana Ernesto Laclau dan Chantal Mouffe}

Teori Wacana lebih membahas kepada faktor linguistik atau bahasa baik lisan maupun tulisan dalam hubungan komunikasi antara komunikator dan komunikan. Dalam teori wacana Laclau dan Mouffe (1985), terdapat tiga unsur yang menggambarkan bagaimana suatu wacana hubungannya dengan lingkungan komunikasi, diantaranya;

1. Titik Nodal: Menurut Laclau dan Mouffe (1985: 112), suatu wacana dibentuk oleh penetapan parsial makna di sekitar titik nodal.
Titik nodal atau Nodal point merupakan sebuah tanda khusus yang dapat mengatur tanda-tanda yang ada di sekitarnya, dimana makna dari tanda-tanda yang ada di sekitarnya ini diperoleh dari adanya hubungan atau keterkaitan dengan titik nodal tersebut. Berdasarkan hal tersebut, dapat dikatakan bahwa titik nodal ini merupakan pusat terbentuknya suatu lingkungan komunikasi atau seperti seorang komunikator yang memberikan informasi kepada komunikan yang ada di sekitarnya.

2. Medan Kewacanaan: Dalam teori wacana Laclau dan Mouffe, wacana merupakan usaha untuk menghentikan tergelincirnya hubungan antara satu tanda dengan tanda yang lainnya sehingga dapat menciptakan sistem makna yang padu, yang juga disebut dengan medan kewacanaan (1985: 111). Medan kewacanaan sendiri merupakan cadangan bagi "surplus makna" yang dihasilkan oleh praktek artikulatoris.

3. Pengakhiran: Teori wacana Laclau dan Mouffe menjelaskan bahwa terdapat konsep pengakhiran, yaitu hentian sementara pada fluktuasi-fluktuasi yang terdapat pada makna tanda-tanda. Namun, pengakhiran itu sendiri tidak pernah pasti. Berdasarkan hal tersebut, wacana tidak pernah bisa sepenuhnya tetap sehingga tidak bisa dirusak atau diubah oleh multisiplas makna yang ada pada medan kewacanaan.

\section{Youtube sebagai Platform}

Ketika awal dibentuk, YouTube hanya sekedar media untuk mengunggah atau berbagi video saja, namun hingga tahun 2018 ini, YouTube sudah memiliki fitur-fitur yang bervariasi, diantaranya fitur untuk melakukan edit online, video 360 derajat, hingga siaran langsung atau live streaming.

Gambar 1 .

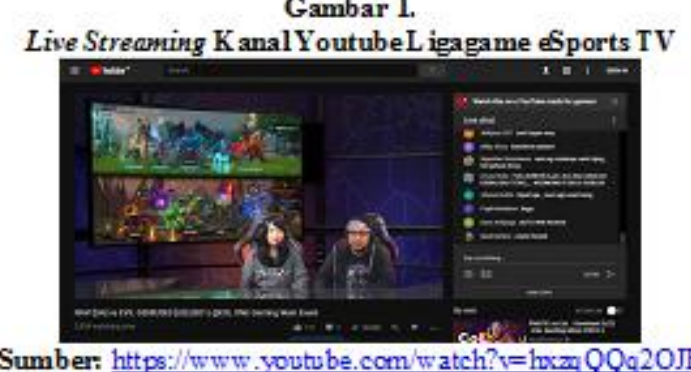

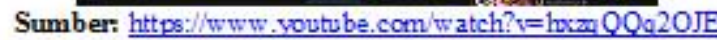

https://www.youtube.com/ch an ne//UCOu ITTSin 8D25nOXVetkzA (diakses pada 23 Januari 2018 pukul 20.01) 
Jika kita lihat channel Ligagame eSports TV pada gambar di atas, kita dapat melihat adanya fitur live chat yang memungkinkan penonton untuk memberikan komentar terhadap konten siaran langsung yang disajikan dan mendapatkan respon dari komunikator sebagai konten kreator atau dari sesama penonton siaran langsung tersebut.

\section{Hate Speech di Youtube}

Hate speech di ranah internet juga termasuk dalam tindakan cyberbullying, dimana menurut Willard (2005) terbagi dalam beberapa jenis berdasarkan bentuk penyampaian ujarannya, seperti; flaming (isi pesan berupa kata-kata kasar dan frontal); harassment (hasil dari tindakan flaming dalam jangka panjang yang berupa perang teks); denigration (menyebarkan keburukan seseorang di media sosial untuk menjatuhkan nama baiknya); impersonation (berpura-pura menjadi orang lain dan bertingkah buruk agar nama baik orang yang digunakannya tercemar); outing (menyebarkan hal pribadi tanpa persetujuan pemiliknya untuk merusak privasi seseorang); trickery (tindakan membujuk dengan tipu daya untuk mendapatkan hal privasi dari orang lain dan digunakan untuk mengintimidasi korbannya); exclusion (tindakan sengaja dan paksa mengeluarkan seseorang dari ruang disukusi atau grup online atau membuat sebuah grup online dan tidak menyertakan orang tersebut); dan cyberstalking (tindakan mengintai aktivitas di dunia maya secara diam-diam yang bertujuan memberi rasa takut pada korbannya dengan memberi pesan yang mengintimidasi).

\section{Caster sebagai Komunikator}

Menurut Yudi Anggi sebagai seorang shoutcaster di dunia eSports dalam artikelnya ${ }^{2}$ menyebutkan bahwa caster dalam prakteknya terbagi atas dua macam, yaitu:

Main Caster: Orang yang menemani jalannya permainan untuk penonton, biasanya lebih kepada membacakan keadaan yang terjadi di game ke penonton.

Co-Caster: Orang yang menjelaskan apa yang terjadi dalam permainan dan melakukan theory crafting mengenai berbagai hal yang ada dalam permainan (Contoh: Pemilihan barang untuk karakter dalam permainan, Strategi tim, dll). Channel YouTube yang peneliti pilih untuk diamati adalah channel YouTube Ligagame eSports TV. Channel ini merupakan channel YouTube yang sering menayangkan siaran langsung pertandingan tim-tim eSports dari game DotA 2, yang merupakan permainan strategi yang dimainkan secara tim melawan tim lainnya dengan lima orang dalam satu timnya. Tujuan utama dari permainan ini adalah memenangkan pertandingan dengan menghancurkan markas utama dari tim lawan.

Hal yang dapat memunculkan bahan untuk dibicarakan adalah bagaimana isi konten dari live streaming ini (performa tim yang bertanding), juga pembawaan dan cara penyampaian pesan dari caster ketika mengomentari jalannya pertandingan. Cara penyampaian dari caster dan isi konten tersebut nanti akan diklasifikasikan ke dalam urutan sesuai teori wacana dari Ernesto Laclau dan Chantal Mouffe, yakni Titik Nodal, Medan Kewacanaan, dan Pengakhiran. Reaksi hate speech dari penonton akan terbagi dalam beberapa macam cyberbullying, seperti Flaming, Harassment, Denigration, Impersonation, Outing dan Trickery. 


\section{Gambar 2.}

Kerangka Pikir

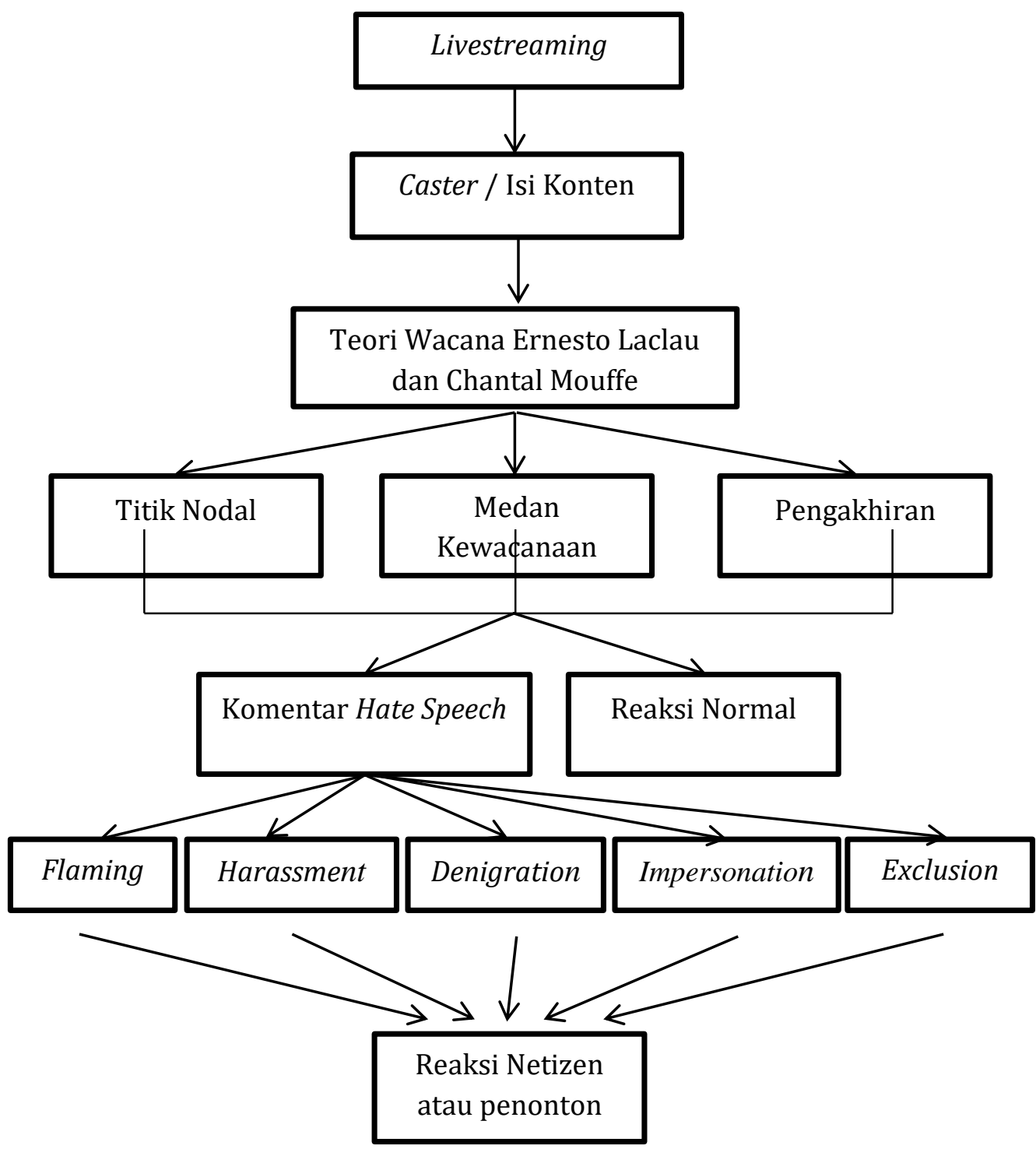

https://medium.com/@yudianggi/menjadi-professional-esports-shoutcaster-caster-8a26e5ca87a5 (diakses pada 22 April 2019 pukul 09:44)

\section{METODE PENELITIAN}

Metode deskriptif dengan pendekatan kualitatif digunakan dalam penelitian ini untuk menjelaskan wacana hate speech yang terbentuk dari interaksi caster dan penontonnya sebagai unit analisis, dan komentar penonton pada live streaming tim Boom ID di OGA Dota PIT Minor 2019 di kanal "Ligagame eSports TV" sebagai unit amatan. Metode pengumpulan data dilakukan dengan wawancara atau interaksi langsung dengan objek penelitian di lapangan. Peneliti juga melakukan triangulasi data sebagai uji kredibilitas data dengan mewawancarai Andi
Fauzan, selaku Kepala Seksi Layanan Data dan Informasi, Dinas Komunikasi dan Informatika (Diskominfo) kota Salatiga, Jawa Tengah.

Menurut Borg dan Gall (1989) metode penelitian kualitatif adalah metode artistik yang proses penelitiannya bersifat seni (kurang terpola) atau biasa disebut sebagai metode interpretive karena data hasil penelitian lebih berkenaan dengan interpretasi terhadap data yang ditemukan di lapangan. Metode penelitian kualitatif juga dapat disebut sebagai metode penelitian naturalistik karena penelitiannya dilakukan pada kondisi yang alamiah (natural setting). Penelitian ini bertujuan menjelaskan 


\section{- $\quad$ Observasi Partisipan}

bagaimana struktur, tatanan, dan proses dari suatu kelompok partisipan dalam lingkungan komunikasi, terutama interaksi yang intens antara komunikator dengan komunikannya. Pemikiran mendasar yang akan peneliti dapatkan nantinya merupakan hasil pengamatan langsung terhadap objek dan latar yang akan diteliti berupa laporan yang sebenar-benarnya, apa adanya, dan catatan-catatan lapangan yang aktual.

Data yang peneliti kumpulkan berasal dari hasil amatan terhadap objek penelitian di lapangan, yaitu aktivitas penonton dalam live streaming, seperti memberikan komentar maupun berinteraksi dengan caster dari channel Ligagame eSports TV melalui kolom komentar langsung (live chat). Peneliti kemudian memilih beberapa komentar dalam siaran live streaming yang bersifat reaktif terhadap pesan yang disampaikan caster, baik yang mengandung konten hate speech maupun komentar biasa.

Jenis data primer peneliti dapatkan dengan menganalisis setiap komentar atau pesan dari penonton berupa konten yang mengandung hate speech pada siaran live streaming channel YouTube "Ligagame eSports TV" pada siaran pertandingan tim Boom ID $^{3}$ di kejuaraan OGA Dota PIT Minor 2019 (tanggal 6 April, dan 2228 April 2019). Sedangkan data sekunder peneliti peroleh dengan mencocokkan setiap wacana hate speech yang muncul dari penonton ketika live streaming berlangsung pada siaran channel YouTube Ligagame eSports TV pada periode OGA Dota PIT Minor 2019 dengan sumber literatur yang berkaitan dengan analisis wacana dari Ernesto Laclau dan Chantal Mouffe, hate speech, maupun cyberbullying.

Dalam mengumpulkan data untuk kepentingan penelitian ini, peneliti menggunakan beberapa metode pengumpulan data, yaitu:

a. Observasi

Nasution (1988) menyatakan bahwa observasi adalah dasar semua ilmu pengetahuan. Para ilmuwan hanya dapat bekerja berdasarkan data, yaitu fakta mengenai dunia kenyataan yang diperoleh melalui observasi. Observasi dengan keterlibatan dengan objek penelitiannya sendiri terbagi menjadi dua, yaitu observasi partisipatif dan observasi non-partisipatif.
Dalam observasi partisipan, observer berperan sebagai pengamat sekaligus menjadi bagian yang diamati.

\section{- Observasi Non-Partisipan}

Dalam observasi non-partisipan observer hanya berperan sebagai pengamat. Fokus dari peneliti ialah untuk mengamati, merekam, memotret, mempelajari, dan mencatat tingkah laku atau fenomena yang diteliti.

Dalam hal ini peneliti menggunakan teknik pengumpulan data berupa observasi nonpartisipan, dimana peneliti fokus mengumpulkan data mengenai interaksi dan reaksi normal maupun yang mengandung konten hate speech yang ada dan menganalisanya dengan beberapa teori pendukung.

b. Dokumentasi

Teknik dokumentasi yaitu mempelajari atau menelaah dokumen-dokumen yang relevan dengan konteks penelitian. Metode dokumentasi yaitu mencari data mengenai hal-hal atau variabel yang berupa catatan, transkrip, buku, surat kabar, majalah, prasasti, notulen rapat, dan lain sebagainya (Arikunto, 2002). Dokumentasi dalam penelitian ini menggunakan screenshot gambar-gambar yang peneliti peroleh dari aktivitas live streaming di channel Ligagame eSports TV. Dokumentasi berupa screenshot interaksi komentar caster yang memunculkan bermacam reaksi dari para penontonnya.

c. Wawancara

Wawancara menurut Arikunto (2002) merupakan dialog yang dilakukan oleh pewawancara untuk memperoleh informasi dari terwawancara atau yang biasa disebut narasumber. Teknik wawancara ini memerlukan pedoman, dimana pedoman wawancara yang akan dilakukan peneliti adalah pedoman wawancara tidak terstruktur yang hanya memuat garis besar yang akan ditanyakan, sehingga membutuhkan kemampuan peneliti untuk menggali lebih dalam dari garis besar yang akan ditanyakan. Wawancara dengan narasumber dari institusi yang memiliki relevansi dengan ranah internet dan konten-konten bernada hate speech, yaitu Dinas Komunikasi dan Informatika (Diskominfo) kota Salatiga, Jawa Tengah.

Instrumen utama penelitian ini menggunakan perangkat elektronik berupa 
laptop atau komputer untuk mengakses siaran channel YouTube Ligagame eSports TV dan

mengambil screenshot dari live streaming tersebut. Nasution (1988) menyatakan bahwa analisa telah dimulai sejak merumuskan dan menjelaskan masalah, sebelum terjun ke lapangan, dan berlangsung terus sampai penulisan hasil penelitian. Namun dalam penelitian kualitatif, analisis data lebih difokuskan selama proses di lapangan bersamaan dengan pengumpulan data. Untuk menganalisa data yang peneliti peroleh melalui observasi dan dokumentasi, maka peneliti melakukan beberapa tahapan sebagai berikut:

a. Menelaah semua data yang peneliti dapatkan dari observasi dan dokumentasi.

b. Mereduksi data yang diperlukan dengan menyeleksi data yang sesuai dengan lingkup penelitian dari peneliti yang berdasar kepada kerangka berpikir.

c. Menyajikan atau memaparkan data.

d. Membuat kesimpulan dari seluruh data yang telah dianalisis.

Menurut Moleong (2007), subjektivitas penelitian merupakan hal utama dalam sebuah kajian penelitian kualitatif, dimana seorang peneliti merupakan sumber dari instrumen penelitiannya, ditambah lagi dengan teknik pengumpulan data dalam penelitian kualitatif ini adalah observasi dan dokumentasi yang dianggap memiliki banyak kelemahan ketika dilakukan secara terbuka dan tanpa ada control. Dalam sebuah penelitian, diperlukan adanya keabsahan data untuk menguji keaslian dari data yang disajikan. Proses pengujian data ini menurut Sugiyono (2012) terbagi menjadi empat tahap, yaitu uji kredibilitas pada proses pengujian keabsahan data merupakan kepercayaan terhadap data hasil penelitian kualitatif yang dapat dilakukan dengan; 1) Perpanjangan pengamatan: Peneliti kembali lagi ke lapangan untuk melakukan pengamatan atau teknik pengambilan data lainnya dengan sumber data yang pernah ditemui atau yang baru sehingga hubungan peneliti dengan narasumber atau sumber data semakin terbentuk dan tidak ada informasi yang disembunyikan lagi; 2) Meningkatkan ketekunan: Melakukan pengamatan lebih cermat dan berkesinambungan sehingga kepastian data dan urutan peristiwa dapat direkam secara sistematis; 3) Triangulasi: Triangulasi dalam uji kredibilitas ini merupakan pengecekan data dari berbagai sumber dengan berbagai cara dan berbagai waktu; 4) Analisis kasus negatif: Merupakan kasus yang tidak sesuai atau berbeda dengan hasil penelitian hingga pada saat tertentu; 5) Menggunakan bahan referensi: Bahan referensi disini merupakan adanya pendukung untuk membuktikan data yang telah ditemukan oleh peneliti; 6) Mengadakan Membercheck: Proses pengecekan data yang diperoleh peneliti kepada sumber atau pemberi data.

\section{HASIL DAN PEMBAHASAN}

\section{Tampilan Komentar Hate Speech Saat Live Streaming.}

Dalam penelitian ini, jenis hate speech yang muncul terdapat dua jenis, yaitu flaming dan exclusion dengan runtutan kronologis dalam beberapa contoh sebagai berikut:

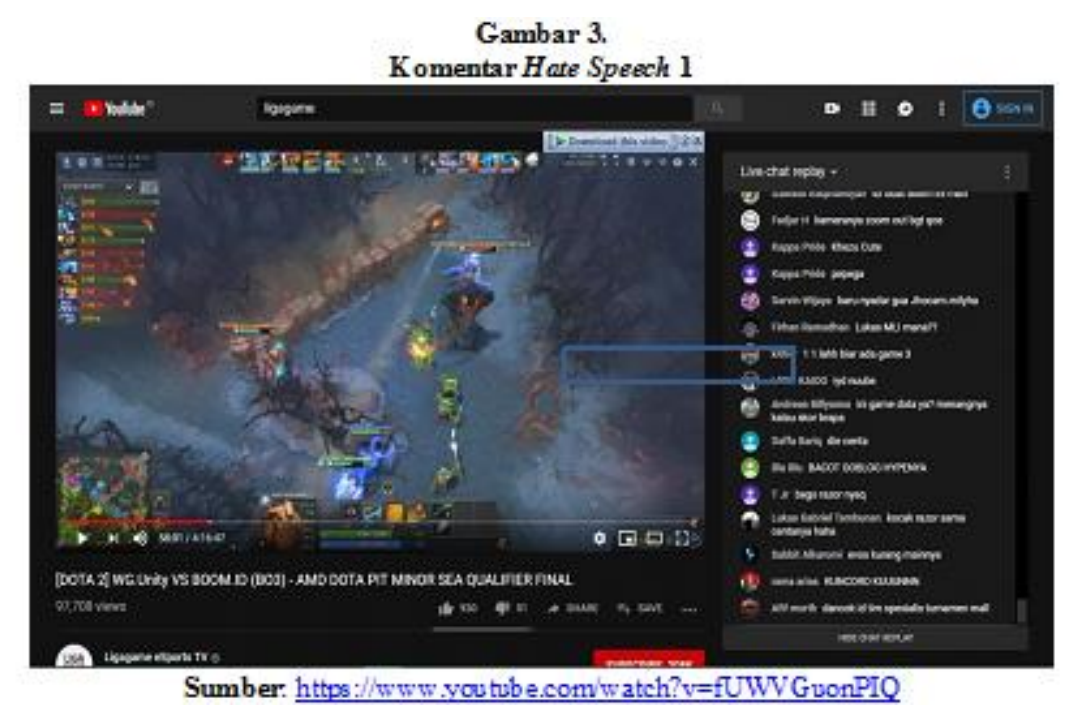


Hal tersebut terjadi ketika dalam pertandingan yang dibawakan oleh Leonardus "R1" Eka, dimana terdapat momen yang menarik antusiasnya dengan berkomentar menggunakan nada yang keras dan cepat. Namun, antusiasme dalam mengomentari jalannya pertandingan mengganggu pemilik akun "Bla Blu" sehingga melontarkan komentar hate speech yang berbunyi "BACOT GOBLOG HYPENYA". Peneliti menilai komentar tersebut mengandung konten hate speech yang masuk dalam kategori flaming (isi pesan berupa kata-kata kasar dan frontal). Pada kata "bacot" dan "goblog" ini termasuk dalam bentuk kekerasan verbal berupa umpatan seperti yang terdapat pada gambar di atas (Mbete, dkk. 2013: 141).

Gambar 4.

Komentar Hate Speech 2

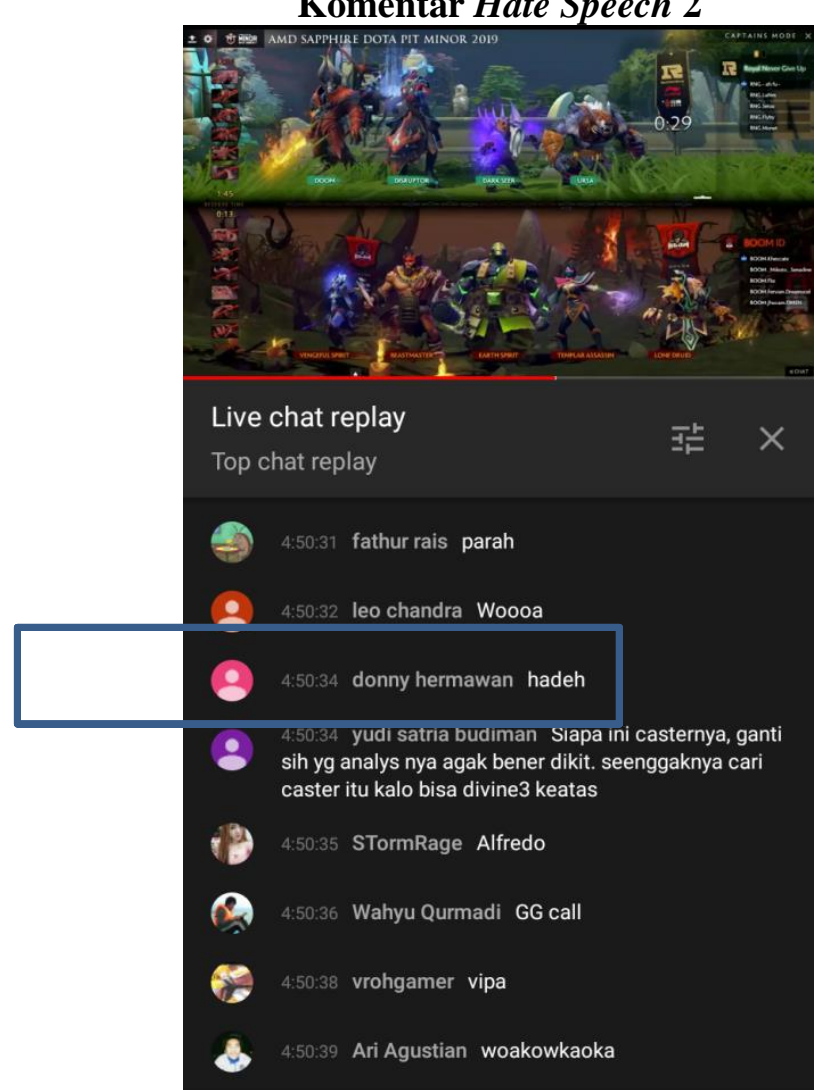

Sumber: https://www.youtube.com/watch?v=NoADV0SZtXg

Komentar tersebut muncul ketika Leonardus "R1" Eka sebagai caster memberikan analisa dan prediksi strategi tim yang bertanding. Namun, pemilik akun bernama Yudi Satria Budiman, merasa analisa caster tidak sesuai standar yang diinginkannya sehingga berkomentar "Siapa ini casternya, ganti sih yang analys nya bener dikit. Seenggaknya cari caster itu kalo bisa divine 3 ke atas" yang termasuk dalam jenis exclusion. Hal tersebut termasuk dalam exclusion (tindakan sengaja dan paksa mengeluarkan seseorang dari ruang disukusi atau grup online atau membuat sebuah grup online dan tidak menyertakan orang tersebut). Dalam kolom komentar di atas jelas adanya tindakan dari penonton (Yudi Satria Budiman) yang meminta untuk mengeluarkan caster (Leonardus Eka) dari lingkungan live streaming.

\section{Reaksi Caster Terhadap Komentar Bernada Hate Speech.}

Kejadian ini terjadi ketika caster pada saat itu yaitu Herliawan "LIM" Lim mengeluhkan jadwal pertandingan yang tidak tepat waktu dan meminta jeda waktu sambil menunggu. 


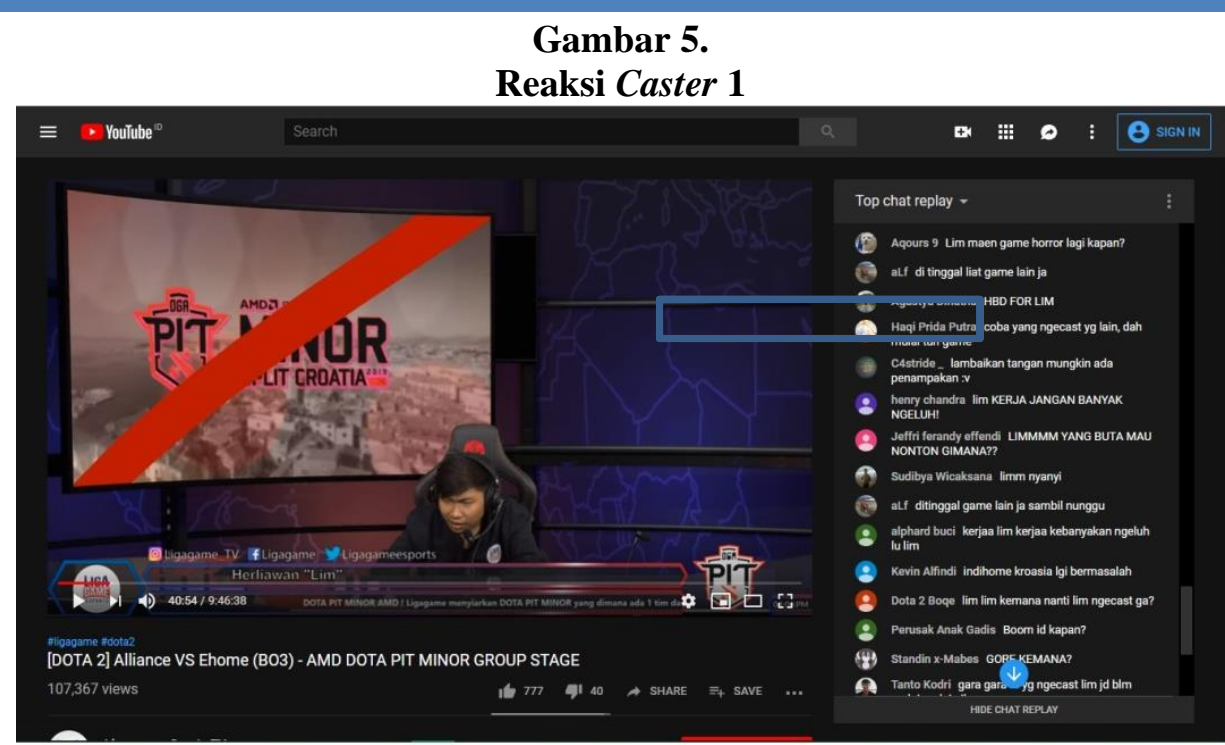

Sumber: https://www.youtube.com/watch?v=ZD3lfRjB9wU

Pemilik akun bernama "Henry Chandra" menganggap tindakan Lim sebagai tindakan mengeluh yang seharusnya tidak dilakukan seorang caster dan memberikan komentar kepada caster berupa "Lim KERJA JANGAN
BANYAK NGELUH! “. Komentar tersebut ditanggapi oleh Lim dengan pernyataan "Biasa aja, udah setengah jam ngomong, capek" dengan nada yang cukup tinggi dan ekspresi wajah yang menahan emosi.

Gambar 6.

Reaksi Caster 2

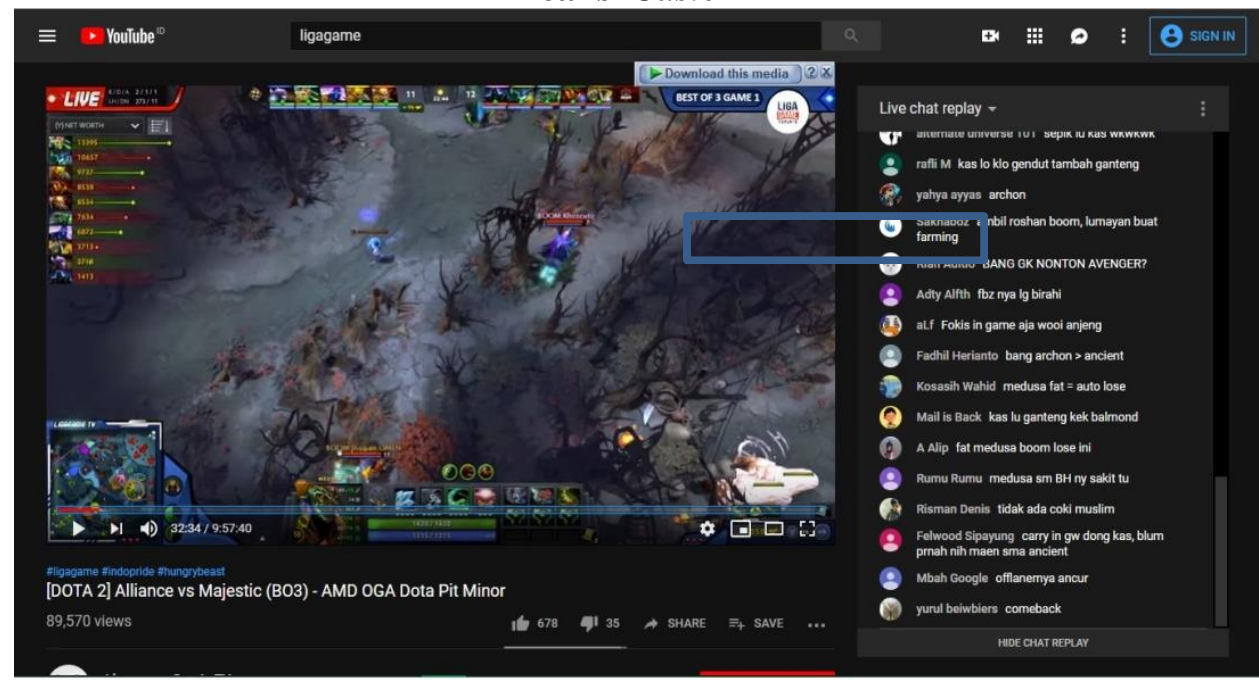

Sumber: https://www.youtube.com/watch?v=K1F1IF9eF3w

Hal ini terjadi ketika Lukas "Mzee" Yanto sebagai caster sedang sedikit bercerita pengalaman pribadinya yang sebenarnya di luar topik yang harus dikomentari. Ternyata pemilik akun bernama aLf memberikan komentar bernada hate speech kepada caster berupa "Fokus in game aja wooi anjeng". Peneliti melihat ada reaksi caster yang mengandung konten hate speech, tepatnya pada penggunaan kata "anjeng" yang merupakan pelesetan dari kata "anjing". Dalam hal ini Lukas (caster) diasosiasikan sebagai "anjing" yang merujuk pada seekor hewan. Kemudian Lukas bereaksi dengan melontarkan pernyataan, "Kenapa anda marah-marah? Kan saya juga sambil bahas game. Emang saya ngomong di luar topik game, full di luar topik? Kan ada in-game nya juga". Peneliti melihat pernyataan tersebut disampaikan dengan nada bicara yang sedikit tinggi namun tidak terlalu cepat. 


\section{Tanggapan Ahli Terkait Konten Bernada Hate Speech dalam Livestreaming}

Untuk melengkapi data penelitian sebagai uji kredibilitas data, peneliti melakukan wawancara dengan Andi Fauzan sebagai
Kepala Seksi Layanan Data dan Informasi, Dinas Komunikasi dan Informasi (Diskominfo), kota Salatiga, Jawa Tengah. Berikut hasil wawancaranya:

1. Tanya : Dengan adanya fenomena hate speech dalam live streaming Youtube, menurut anda bagaimana wacana yang ditampilkan seorang caster sebagai komunikator sehingga menimbulkan reaksi berupa komentar hate speech?

Jawab : Harus diperhatikan dahulu dari caster apakah ada unsur kesengajaan dari pembawaannya (Gestur dan pesan yang disampaikan) sebagai caster yang memancing reaksi hate speech dari penontonnya, bisa saja sebenarnya pesan yang disampaikan caster merupakan pernyataan yang biasa atau normal namun karena ini merupakan ranah online dimana bersifat bebas atau tidak ada aturan-aturan sehingga penonton bisa menganggap pernyataan tersebut mengundang hate speech. Ketika sudah masuk dalam streaming, reaksi penonton bersifat langsung sehingga tidak dapat dibatasi.

2. Tanya : Setelah melihat contoh nyata dari temuan saya mengenai adanya hate speech di livestreaming Youtube, menurut Bapak Andi bagaimana seharusnya seorang caster sebagai komunikator membawakan dirinya ke dalam lingkungan komunikasi online ini agar dapat meminimalisir munculnya reaksi berupa komentar hate speech?

Jawab : Seorang caster ada baiknya untuk tidak terpancing dengan penonton yang berusaha mengganggu dengan komentar hate speech. Caster harus bisa memposisikan dirinya sebagai pemegang topik, jangan sampai diarahkan penonton. Sebagai caster jika merasa komentar penonton tidak sesuai dengan topik dapat diabaikan saja atau dialihkan ke topik lainnya.

3. Tanya : Jika berbicara mengenai hate speech, menurut anda seperti apakah tolok ukur sebuah komentar dapat dikatakan sebagai komentar yang mengandung hate speech? Apakah ketika seorang caster sebagai komunikator merasa tersinggung lalu komentar tersebut secara otomatis termasuk dalam komentar hate speech?

Jawab : Hate speech secara umum sifatnya merugikan atau melukai orang lain secara fisik atau non-fisik. Secara hukum, sebuah komentar dapat dikatakan termasuk hate speech ketika adanya laporan ke aparat hukum mengenai komentar hate speech dan aparat hukum mengkonfirmasi bahwa komentar tersebut termasuk hate speech. Jika dilihat dari sisi norma dan etika, komentar-komentar yang termasuk hate speech seperti umpatan, dan lain-lain tentu merupakan hal yang bermasalah. Namun, komentar yang sebenarnya termasuk dalam hate speech tidak menjadi masalah ketika caster maupun penonton menganggapnya sebagai komentar yang normal.

Setelah dilakukan penjabaran mengenai analisa hate speech dalam live streaming kanal Ligagame eSports TV hingga triangulasi data, penelitian ini mendapati hasil akhir analisa yang dicocokkan dengan teori wacana Laclau dan Mouffe, yaitu:

\section{Titik Nodal}

: Titik nodal dalam teori wacana Laclau dan Mouffe merupakan pusat berkumpulnya tanda-tanda yang maknanya saling berhubungan dalam lingkungan komunikasi, dimana dalam penelitian ini caster Ligagame eSports TV yang memiliki gestur, gaya dan nada bicara tertentu sebagai komunikator. Caster sebagai titik nodal akan mengatur makna seperti apa yang dapat masuk atau tidak ke dalam lingkungan live streaming yang dibawakannya. Caster pertama adalah Herliawan Lim dengan pembawaan berupa ekspresi wajah yang datar dan nada bicara yang tidak terlalu terdengar antusias, serta pembicaraannya sesekali di luar topik yang dibawakannya. Caster selanjutnya 
2. Medan Kewacanaan

\section{Pengakhiran}

\section{KESIMPULAN DAN SARAN}

\begin{abstract}
Berdasarkan hasil penelitian, dapat disimpulkan bahwa wacana hate speech akan tetap muncul sebagai hasil interaksi antara caster sebagai komunikator dan penonton sebagai komunikan meskipun caster sudah memiliki pembawaan sebagai titik nodal lingkungan komunikasi dalam live streaming dengan gestur dan nada bicara yang datar maupun atraktif dan ekspresif.
\end{abstract}

- maupun atraktif dan ekspresif. adalah Leonardus Eka dengan pembawaan berupa gestur yang santai, nada bicara yang tinggi dan cepat ketika terjadi hal yang menarik pada pertandingan tersebut sehingga penonton merasa antusias, dan pembicaraan yang selalu terfokus pada topik yang dibawakannya. Caster lainnya adalah Lukas Yanto dengan pembawaan dari ekspresi wajah yang ekspresif dan nada bicara yang variatif sehingga terdengar ekspresif pula, serta pembicaraan selama live streaming seringkali membahas hal-hal yang bukan merupakan topik dari live streaming. Caster terakhir adalah Alvino Christian dengan pembawaan ekspresi wajah dan nada bicara yang cukup datar, namun sangat fokus terhadap apa yang dibawakannya dalam live streaming dengan analisisnya.

Pada penelitian ini, yang merupakan medan kewacanaan adalah komentar-komentar hate speech yang ditujukan kepada caster maupun komentar yang dianggap caster merupakan hate speech dan memberikan reaksi terhadap komentar tersebut. Komentarkomentar bernada hate speech yang ada selama siaran Ligagame eSports TV ini menurut Willard (2005) termasuk dalam jenis cyberbullying dengan kategori flaming dan exclusion, dimana untuk kategori flaming menurut Mbete, dkk (2013) kebanyakan berupa umpatan dengan kata kasar dan asosiasi terhadap hewan. Pada penelitian ini, proses pengakhiran terlihat dari bagaimana seorang caster menangani adanya hate speech yang terdapat dalam live streaming dan ditujukan pada caster. Dalam menangani hate speech, caster Ligagame eSports TV melakukan beberapa hal, seperti membalas secara langsung hate speech yang ditujukan padanya seperti yang dilakukan Lukas Yanto ketika ada umpatan yang ditujukan padanya dengan ekspresi dan nada bicara yang menunjukkan rasa kesal juga. Hal yang lain adalah dengan konfirmasi agar tidak terjadi pemahaman yang berbeda, seperti yang dilakukan Herliawan Lim ketika membalas umpatan terhadapnya dengan menjelaskan alasan ia mengeluh ketika live streaming. Cara lain yang dilakukan caster Ligagame eSports TV adalah dengan menawarkan solusi atas hal membuat munculnya hate speech seperti yang dilakukan Leonardus Eka dengan menawarkan penonton tersebut untuk bertanding langsung dengan tim yang ia anggap tidak pantas berada di turnamen tersebut. Hal terakhir yang dilakukan caster Ligagame eSports TV untuk mengatasi hate speech adalah dengan mengabaikan atau tidak membalas komentar tersebut dan tetap fokus membuat live streaming berjalan lancar seperti yang dilakukan Alvino Christian.
Dalam hal ini titik nodal merupakan sebuah tanda khusus yang dapat mengatur tanda-tanda yang ada di sekitarnya, dimana makna dari tanda-tanda yang ada di sekitarnya ini diperoleh dari adanya hubungan atau keterkaitan dengan titik nodal tersebut. Berdasarkan hal tersebut, dapat dikatakan bahwa titik nodal ini merupakan pusat terbentuknya suatu lingkungan komunikasi atau seperti seorang komunikator yang memberikan informasi kepada komunikan yang ada di sekitarnya. 
Terkait dengan penelitian ini titik nodal terjadi karena penonton di dunia maya (internet) yang sifatnya anonim, dimana mereka merasa aman untuk mengungkapkan hate speech atau ujaran kebencian. Selain itu, hal yang kemudian dilakukan seorang caster dalam penelitian ini dengan menanggapi komentar-komentar hate speech merujuk pada konsep pengakhiran dalam teori wacana Laclau dan Mouffe, yaitu hentian sementara pada fluktuasi-fluktuasi yang terdapat pada makna tanda-tanda. Namun, pengakhiran itu sendiri tidak pernah pasti.

Berdasarkan hal tersebut, wacana tidak pernah bisa sepenuhnya tetap sehingga tidak bisa dirusak atau diubah oleh multisiplas makna yang ada pada medan kewacanaan. Dalam penelitian ini peneliti melihat bahwa konfirmasi atas pernyataan yang berpotensi menjadi salah paham, beradu argumen, memberikan solusi terakhir atas penyebab penonton melontarkan komentar hate speech, atau dapat mengabaikan komentar tersebut. Sementara itu, peneliti menyadari terdapat kekurangan dalam penelitian ini yang hanya membatasi penelitian pada wacana komunikasi dengan unsur komunikator, pesan, dan komunikan di dalamnya. Karena itu peneliti berharap penelitian selanjutnya dapat melengkapi dan menyempurnakan penelitian ini dengan melihat bagaimana efek atau dampak dari komentarkomentar yang mengandung konten hate speech bagi caster itu sendiri.

\section{DAFTAR PUSTAKA}

\section{Sumber Buku:}

Alkali, Terfa T., Hemen Philip Faga, \& Jinatu Mbursa. 2017. Audience Perception of Hate Speech and Foul Language in the Social Media in Nigeria: Implication for Morality and Law.

Academicus International Scientific Journal 15: 161-178.

Anam, M. Choirul dan Hafiz, Muhammad. 2015. Surat Edaran Kapolri Tentang Penanganan Ujaran Kebencian (Hate Speech) Dalam Kerangka Hak Asasi Manusia. Jurnal Keamanan Nasional 1(3): 341-364.
Arikunto, Suharsimi. 2006. Metodologi Penelitian. Yogyakarta: Bina Aksara.

Asmarawan, Akbar Muslim Syarif. 2016. Analisis Isi Pesan Permasalahan Sosial dalam Internet Meme (Studi Deskriptif Kuantitatif Pesan Permasalahan Sosial dalam Internet Meme di Fan Page Meme Comic Indonesia periode November 2015). Skripsi. Universitas Islam Negeri Sunan Kalijaga. Yogyakarta.

Borg, W.R. dan Gall, M.D. 1989. Educational Research: An Introduction, Fifthy Edition. New York: Longman.

Gunawan, Imam. 2016. Metode Penelitian Kualitatif: Teori dan Praktik. Jakarta: Bumi Aksara.

Helpiastuti, Selfi Budi. 2016. Media Sosial dan Perempuan (Analisis Wacana terhadap Facebook Sebagai Media Komunikasi Terkini Bagi Perempuan). Skripsi. FISIP Universitas Jember. Jember.

Jorgensen, Mariane W. dan Louise J. Phillips. 2007. Analisis Wacana: Teori dan Metode. Yogyakarta: Pustaka Pelajar.

Maiyulinda, Catur. 2018. Analisis Wacana Berita Liputan Khusus Kaltim Post tentang Pesta Pora di Tahura terhadap Kecenderungan Media dalam Menyadarkan Masyarakat Mengenai Penambangan Ilegal. eJournal Ilmu Komunikasi 6(1): 158-172.

Mbete, Aron Meko. et.al. Dinamika Bahasa Media Televisi, Internet, dan Surat Kabar. Denpasar: Udayana University Press.

Moleong, Lexy J. 2013. Metodologi Penelitian Kualitatif. Bandung: Remaja Rosdakarya.

Morissan. 2013. Teori Komunikasi: Individu Hingga Massa. Jakarta: Prenadamedia Group.

Nasrullah, Rulli. 2015. Media Sosial: Prosedur, Tren, dan Etika. Bandung: Simbiosa Rekatama Media. 
Nasrullah, Rulli. (2015). Media Sosial: Perspektif Komunikasi, Budaya, dan Sosioteknologi. Simbiosa Rekatama Media. Bandung.

Nasution, S. 1988. Metode Penelitian Naturalistik Kualitatif. Bandung: Tarsito.

Sari, Maya. 2013. Potret Relasi Dosen dan Mahasiswa dalam Tumblr "YeahMahasiswa" (Sebuah Analisis Wacana Kritis Norman Fairclough). Skripsi. Universitas Kristen Satya Wacana. Salatiga.

Steffgen, G. et.al. 2011. Are Cyberbullies Less Empathic? Adolescents' Cyberbullying Behavior and Empathic Responsiveness. Jurnal Cyberpsychology, Behavior, and Social Networking 14(11): 643-648.

Sugiyono. 2007. Metodologi Penelitian Pendidikan. Bandung: Alfabeta.

2012. Metode Penelitian Kuantitatif, Kualitatif, dan R\&D. Bandung: Alfabeta.
Willard, Nancy E. 2007. Cyberbullying and Cyberthreats: Responding to the Challenge of Online Social Aggression, Threats, and Distress. Amerika Serikat: Malloy.

Yohan. 2016. Hate Speech dan Dampak Media Sosial terhadap Perkembangan Komunikasi Akademik. Mawa'izh 1(2): 309-334.

\section{Sumber Internet:}

Al-Arief, Triyono. 2013. Book Review: Analisis Wacana, Teori, dan Metode. https://www.kompasiana.com/batiksolo85.tok obagus.com/book-review-analisis-wacanateori-dan-

metode_5530010f6ea83467048b45a5.

Diunduh pada 16 Juni 2018 jam 20:35.

Anggi, Yudi. 2016. Menjadi Professional Esports Shoutcaster / Caster.

https://medium.com/@yudianggi/menjadiprofessional-esports-shoutcaster-caster8a26e5ca87a5. Diunduh pada 22 April 2019 jam 09:44 